\title{
A Possible Reduction in the Severity of Typhoon Wind in the Northern Part of Japan under Global Warming: A Case Study
}

\author{
Rui Ito ${ }^{1}$, Tetsuya Takemi ${ }^{1}$, and Osamu Arakawa ${ }^{2}$ \\ ${ }^{1}$ Disaster Prevention Research Institute, Kyoto University, Kyoto, Japan \\ ${ }^{2}$ University of Tsukuba, Tsukuba, Japan
}

\begin{abstract}
Typhoon Songda (2004), while undergoing an extratropical transition and reintensification over the Sea of Japan, spawned serious damages over forest areas in the northern part of Japan. To clarify influences of anticipated global warming on the typhoon hazard in high-latitude regions, we carried out numerical experiments on Typhoon Songda in a current climate and a pseudo global warming climate and examined the impacts of climate change on the typhoon intensify and windstorms for the region. The typhoon intensity at its maturity becomes stronger in a warming climate, and the typhoon while passing over the Sea of Japan weakens more rapidly in the warming climate. Thus the strong wind over the northern part of Japan in the warming climate also becomes weaker. We examined atmospheric environmental factors in the higher-latitude region: sea surface temperature, vertical shear, and meridional gradient of temperature. It was found that the environmental meridional gradient of temperature at the 500 $\mathrm{hPa}$ level is smaller in the warming climate than in the current climate, which indicates that the baroclinicity becomes weak under global warming. The weak baroclinicity makes the typhoon environment unfavorable for the extratropical transition, and therefore, possibly reduces the severity of typhoon wind in northern Japan.

(Citation: Ito, R., T. Takemi, and O. Arakawa, 2016: A possible reduction in the severity of typhoon wind in the northern part of Japan under global warming: A case study. SOLA, 12, 100-105, doi:10.2151/sola.2016-023.)
\end{abstract}

\section{Introduction}

Understanding the influences of climate change on tropical cyclones (TCs) is one of the major challenges from the viewpoint of not only scientific concerns but also impact assessments of climate change on natural hazard. Increases in the intensity and frequency of typhoons under global warming have been discussed (Knutson et al. 2010). In the Fifth Assessment Report of the Intergovernmental Panel on Climate Change, it is projected that in a future warming climate the global frequency of TCs decreases or stays constant and the strongest TCs become stronger (Christensen et al. 2013). However, the level of the certainties in the projections is lower depending on regions. Murakami et al. (2012) indicated that the global frequency of intense TCs is projected to increase and the frequency of TCs will increase or decrease varying with the part of the Pacific using the Meteorological Research Institute Atmospheric General Circulation Model (MRI-AGCM). Therefore, assessments for the influence of the warming should be conducted region by region.

Damages by TCs become more significant in the regions where TCs seldom approach or make landfall, especially in the higher-latitude regions. Furthermore, in the case of undergoing an extratropical transition the damages become more severe, such as in the cases of Typhoon Mireille (1991), Typhoon Songda (2004) and Hurricane Sandy (2012) (Gary 2015; Fujibe et al. 2006; Kitabatake et al. 2007). Typhoon Marie (1954) and Typhoon Songda passes over the northern part of Japan, including Hokkaido and

Corresponding author: Rui Ito, Disaster Prevention Research Institute, Kyoto University, Gokasho, Uji, Kyoto 611-0011, Japan. E-mail: rui.ito@ storm.dpri.kyoto-u.ac.jp. (C2016, the Meteorological Society of Japan. caused severe disasters on human lives, agriculture, and industries.

Typhoon Songda underwent an extratropical transition and reintensification while it passed over the Sea of Japan and Hokkaido (Fujibe et al. 2006; Kitabatake et al. 2007). Instantaneous wind speed marked the new record at more than half of the observation sites in Hokkaido. The peak gust was $51.5 \mathrm{~m} \mathrm{~s}^{-1}$ at a site in northeast Hokkaido. Widespread forest damages by the windstorm were serious problem on the ecosystems (Sano et al. 2010; Hayashi et al. 2015). Because it is anticipated that extreme typhoons become more intensified under future global warming, it is important to understand the impacts of climate change in higher-latitude regions on the intensity of typhoons and the resultant hazard.

The environmental factors that induce extratropical transition have been demonstrated in previous studies. Klein et al. (2000) presented a conceptual model for the transition using the transitions in the western North Pacific. Jones et al. (2003) showed a process of the transition based on Klein et al. (2000) and presented the relevant environmental factors. Kitabatake (2013) indicated that the atmospheric environment transforms the typhoon structure, and additionally, the system needs to have characters of an extratropical cyclone to complete the transition. After the transition, some of the system occasionally happen to reintensify. Based on these studies, this study focuses on the environmental conditions for Typhoon Songda.

This study investigates the influences of climate change on the severity of a typhoon in the northern part of Japan by conducting numerical experiments for Typhoon Songda as a case study. The experiments were carried out for two different climate conditions: real atmospheric condition in September 2004 as a current climate and a pseudo global warming (PGW) condition as a future September climate. Here, we focused on the severe windstorm by Typhoon Songda over Hokkaido. Additionally, we discussed the impacts of climate change on the typhoon intensity and the windstorm by considering changes in the environmental factors presented by Jones et al. (2003).

\section{Experimental design}

The numerical experiments for Typhoon Songda were performed with the Weather Research and Forecasting (WRF) model version 3.6.1 (Skamarock et al. 2008). The computational domain covers the region with $13.7^{\circ} \mathrm{N}-51.7^{\circ} \mathrm{N}$ and $111.1^{\circ} \mathrm{E}-168.9^{\circ} \mathrm{E}$ for the outermost domain, that with $38.1^{\circ} \mathrm{N}-46.6^{\circ} \mathrm{N}$ and $135.9^{\circ} \mathrm{E}-$ $148.0^{\circ} \mathrm{E}$ for the intermediate domain and that with $41.1^{\circ} \mathrm{N}-45.4^{\circ} \mathrm{N}$ and $139.6^{\circ} \mathrm{E}-146.6^{\circ} \mathrm{E}$ for the innermost domain. The grid interval for each domain is $9 \mathrm{~km}, 3 \mathrm{~km}$ and $1 \mathrm{~km}$. We applied the two-way nesting technique between the parent and the child domain. The number of vertical levels is 57 and the model top is $20 \mathrm{hPa}$. KainFritsch scheme was used every 10 minute as a cumulus scheme for the outermost domain. WRF single-moment 6-class scheme (Hong and Lim 2006) was employed as a microphysics scheme. It is important for the representation of surface wind to adequately select a planetary boundary layer physics scheme. Because MellorYamada-Janjic scheme was utilized for representing extreme weather due to Typhoon Songda in Oku et al. (2010), the scheme was selected here.

The experiment for the outermost domain was initialized at 0000 UTC 3 September 2004. The time integration was started at 0000 UTC 5 September for the intermediate domain, and at 
0000 UTC 7 September for the innermost domain. The initial and lateral boundary data were provided from the Japanese 55-year reanalysis (JRA-55) dataset with spatial resolution of $1.25^{\circ}$ and time interval of 6 hour (Kobayashi et al. 2015). To impose influences of synoptic-scale atmospheric conditions on the computational area, the spectral nudging option was imposed on the horizontal wind above the $700-\mathrm{hPa}$ level on the outermost domain. The maximum wavenumber nudged is 2 and the nudging coefficient is $0.00028 \mathrm{~s}^{-1}$. A typhoon bogus scheme was introduced for better representing the typhoon intensity at the initial time. The bogus scheme inserts a synthetic Rankin vortex using information for maximum wind (Davis and Low-Nam 2001). We set the maximum wind speed, $70 \mathrm{~m} \mathrm{~s}^{-1}$, at the radius of $75 \mathrm{~km}$ from the center for the synthetic vortex by reference to the observed data of the Regional Specialized Meteorological Center (RSMC) TokyoTyphoon Center.

The future condition for the PGW climate was made by adding the global-warming increments of the future climate from the current climate on the initial and boundary condition produced from JRA-55 (Sato et al. 2007). The climate data are the simulated results by MRI-AGCM version 3.2 with $20-\mathrm{km}$ resolution (Mizuta et al. 2012). AGCM simulations were carried out with the use of the ensemble means and three clusters of sea surface temperature (SST) for the future climate simulations (Mizuta et al. 2014). All the SST clusters as well as the ensemble mean under the RCP8.5 scenario were utilized for the PGW simulations. Because Typhoon Songda occurred in September, the current and future monthly means of September were obtained from the AGCM results over 1979-2003 and 2075-2099, respectively. The increment means the difference in their two monthly mean values. The warming increments considered here are surface air temperature, SST, surface pressure, and sea level mean pressure for the surface variables, and geopotential height and temperature for the three-dimensional variables. We did not add the difference of relative humidity, because there is no significant difference between the current and future climate (e.g. Takemi et al. 2012). We also did not add the increments of winds in order to prevent unwanted effects of wind field on the track of the typhoon, such as deflecting the future track from the current track. By taking the increments of winds out of consideration, concerns about the dynamic balance of the atmosphere may arise; however, there were few unpractical issues at carrying out this experiments for the purpose of the impact assessment. The horizontal distributions of the increment about the surface variables, and the vertical profile of the temperature increment are shown in Fig. 1.

In the PGW experiments for the ensemble-mean SST warming, we examined two cases: an addition of the increments on all the above variables (Case I) and an addition of the increments only on surface air temperature, SST, and temperature (Case II). We also conducted the PGW experiments with the three pattens of the SST warming for taking into account the uncertainty of the projected future climate due to different SST patterns. In these PGW experiments, we added the warming increments of SST and temperatures. The experiments are referred to Case IIa, IIb, and IIc for the Cluster 1, 2, and 3, respectively in the study of Mizuta et al. (2014). The spatial distributions of the increments in the cases are illustrated in Supplement 1.

\section{Results}

Figure 2 shows the tracks and central pressures of the simulated typhoons, which are compared with the best-track data of the RSMC Tokyo-Typhoon Center. The track of the simulated typhoon in the current climate seems to be shifted westward from the best track over the Sea of Japan (Fig. 2a). Kitabatake et al. (2007) shows by using polar-orbiting satellites data that the possible cyclone centers are shifted westward from the best track. The track under the current condition in this study is actually close to the path estimated from the satellite. The central pressure of

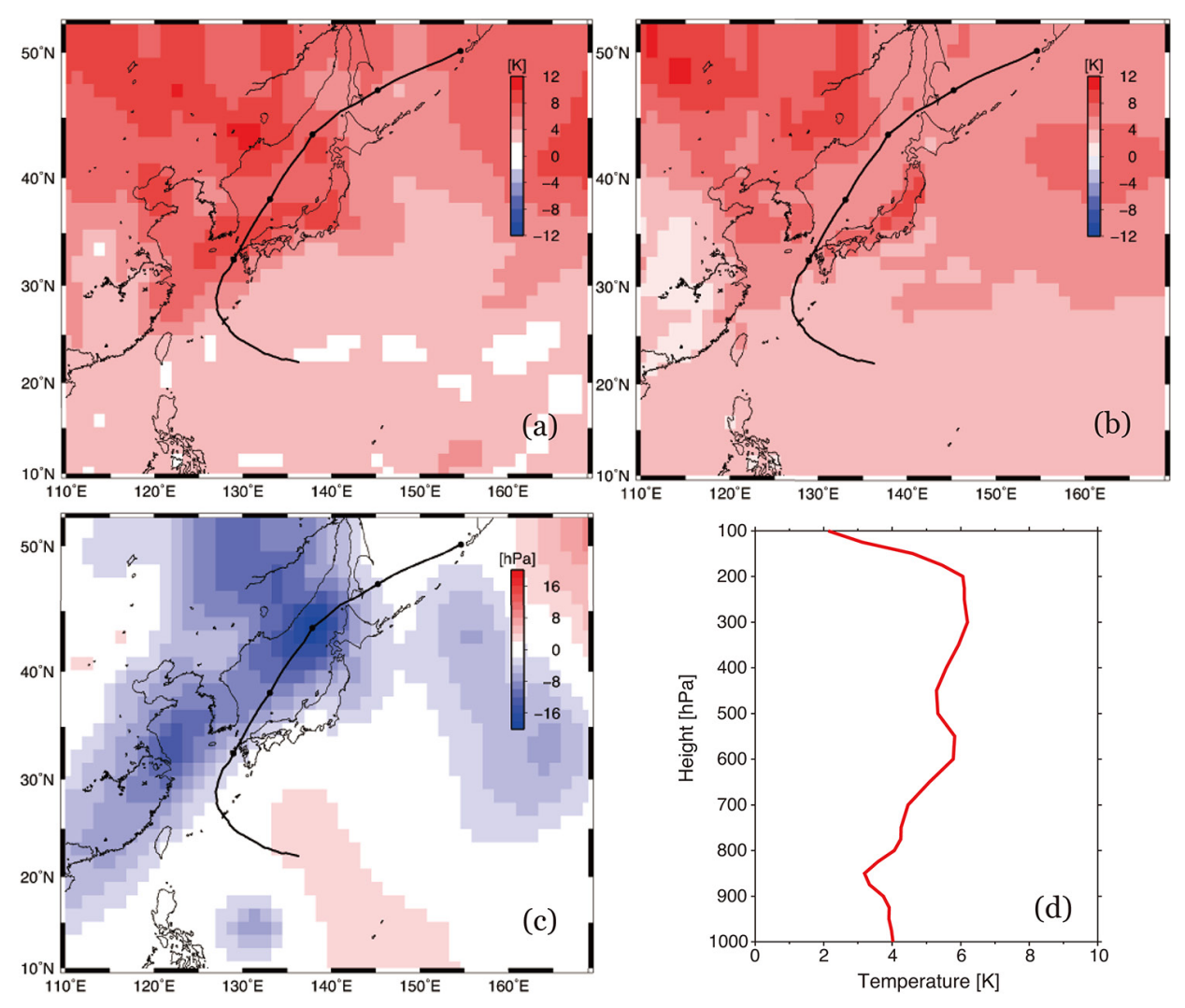

Fig. 1. Spatial distributions of the increment for the future global warming for (a) surface air temperature (K), (b) SST (K), and (c) surface pressure (hPa). (d) The vertical profile of mean temperature increment $(\mathrm{K})$ averaged over the area of $130^{\circ} \mathrm{E}-140^{\circ} \mathrm{E}$ and $35^{\circ} \mathrm{N}-45^{\circ} \mathrm{N}$. Black line is the simulated typhoon track in the current climate. 

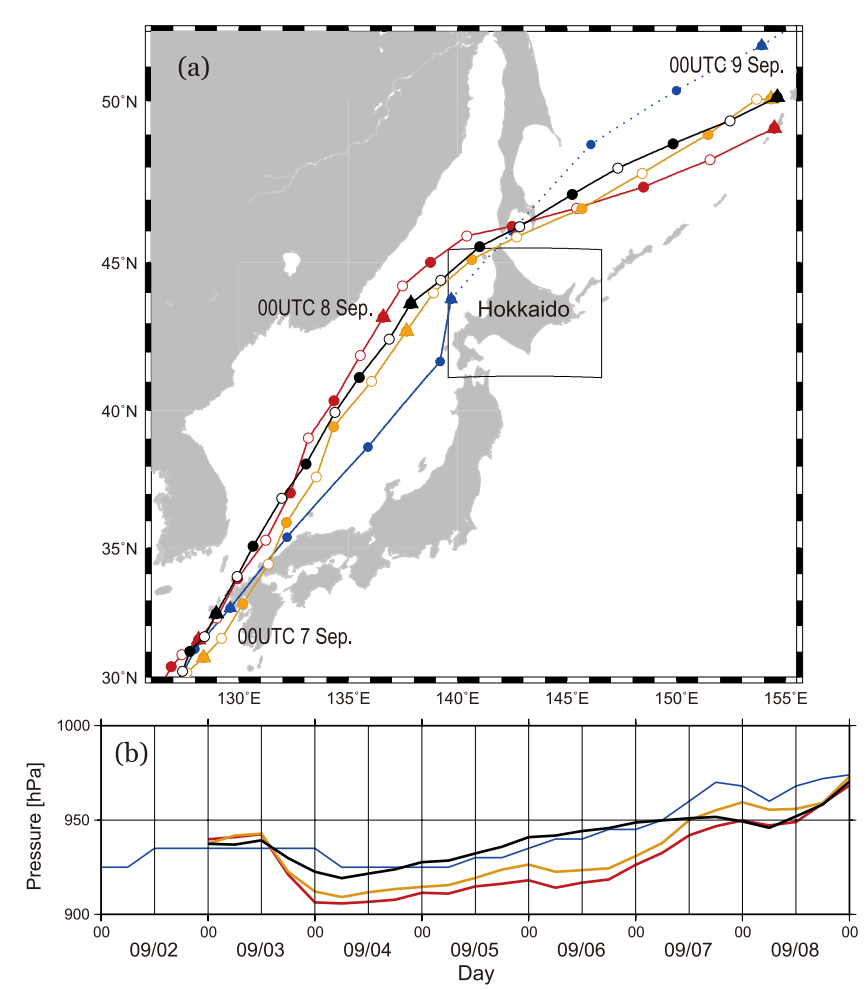

Fig. 2. (a) Best-track and tracks of the simulated typhoons. The besttrack data area indicated by blue and the simulated data by black (current climate), red (PGW-Case I), and orange (PGW-CaseII). Triangle indicates the typhoon position every 24-hr from 0000 UTC 7 Sep. Closed circle indicates the position at 0600 UTC, 1200 UTC, and 1800 UTC, and open circle indicates that at 0300 UTC, 0900 UTC, 1500 UTC and 2100 UTC. Square indicates the innermost domain. (b) Time series of the central pressures of the best-track (blue) and the simulated typhoons (current climate; black, PGW-Case I; red, and PGW-CaseII; orange).

the typhoon under the current climate increases from 0600 UTC 4 September to 1800 UTC 7 September, and it subsequently decreases until 0600 UTC 8 September (Fig. 2b). This temporal change is consistent with that by Kitabatake et al. (2007).

Under the PGW condition, the typhoon in Case I (Case II) passes west (east) of the track in the current climate (Fig. 2a). It is seen that the track in Case II is a little closer to the track in the current climate than the track in Case I around the northern part of Japan and in Hokkaido. The increment of surface pressure over the northern part of the Sea of Japan is regionally large owing to the regional difference of the horizontal distribution between the current climate and the future climate (Fig. 1c). The effects of the large pressure increment on the typhoon track do not appear clearly because the increment of winds is left out of account.
Table 1. Minimum central pressure $\left(P_{\min }\right)$ and local minimum of the pressure on 8 September $\left(P_{\text {local }}\right)$.

\begin{tabular}{ccccccc}
\hline \multirow{2}{*}{ Case } & Current & \multicolumn{5}{c}{ Pseudo Global Warming } \\
\cline { 3 - 7 } & & I & II & IIa & IIb & IIc \\
\hline$P_{\min }(\mathrm{hPa})$ & 919 & 906 & 909 & 913 & 906 & 907 \\
$P_{\text {local }}(\mathrm{hPa})$ & 946 & 947 & 955 & 957 & 957 & 一 $^{*}$ \\
\hline
\end{tabular}

*No local minimum.

In terms of the central pressure, the simulated typhoons in the PGW experiments become stronger by more than $10 \mathrm{hPa}$ than the simulated typhoon in the current climate during the period from 1800 UTC 3 September to 1200 UTC 7 September (Fig. 2b, Table 1). This indicates the particular typhoon at its maturity would be more intensified in the PGW condition. On the other hand, the simulated typhoons under the PGW climate more quickly weaken after 1200 UTC 6 September. The pressures in the PGW climates become comparable to or higher than that in the current climate around 0000 UTC 8 September when the typhoon is located close to Hokkaido (Table 1). The reason why the central pressure in PGW-Case I does not increase as that in PGW-Case II from 1200 UTC 7 September to 1200 UTC 8 September is the distribution of low pressure anomaly over the Sea of Japan which is shown in Fig. 1c. The anomaly suppresses an increase of the central pressure. The decrease in the pressure from 2100 UTC 7 September to 0600 UTC 8 September is $5.6 \mathrm{hPa}$ in the current climate, $3.7 \mathrm{hPa}$ in Case I, and $4.8 \mathrm{hPa}$ in Case II. Therefore, the typhoons under the warming climate are weakened and the reintensifications also become reduced. In the following, we mainly compared the strong wind by the typhoon between the current climate and Case II of the PGW climate because of the better reproduction of the typhoon track with the current climate.

To present the warming impacts on the surface winds, the difference of wind speed in the PGW climate from that in the current climate is depicted in Fig. 3. The current and the future wind averaged over the land areas in the innermost domain at 0600 UTC 7 September (Fig. 3a) is $3.4 \mathrm{~m} \mathrm{~s}^{-1}$ and $3.8 \mathrm{~m} \mathrm{~s}^{-1}$, respectively. Thus the wind becomes strengthened due to the warming at this time. The central pressure of the typhoon is lower in the warming climate than in the current climate at the time (Fig. 2b). At the later time (Figs. 3b, c), the wind speed averaged over the land areas is lower in the warming climate because of the weakened typhoon. The maximum difference, $-5.9 \mathrm{~m} \mathrm{~s}^{-1}$, is recorded at $0000 \mathrm{UTC}$ 8 September during a day from 0600 UTC 7 September (not shown).

Table 2 summarizes spatial means averaged over the land areas for the temporal average and the maximum wind for each grid during the period from 0300 UTC 7 September to 0000 UTC 9 September. The averaged wind speeds are lower in Case I and II than in the current climate, and the speeds are also lower under the different future patterns of SST. The same feature can be found for
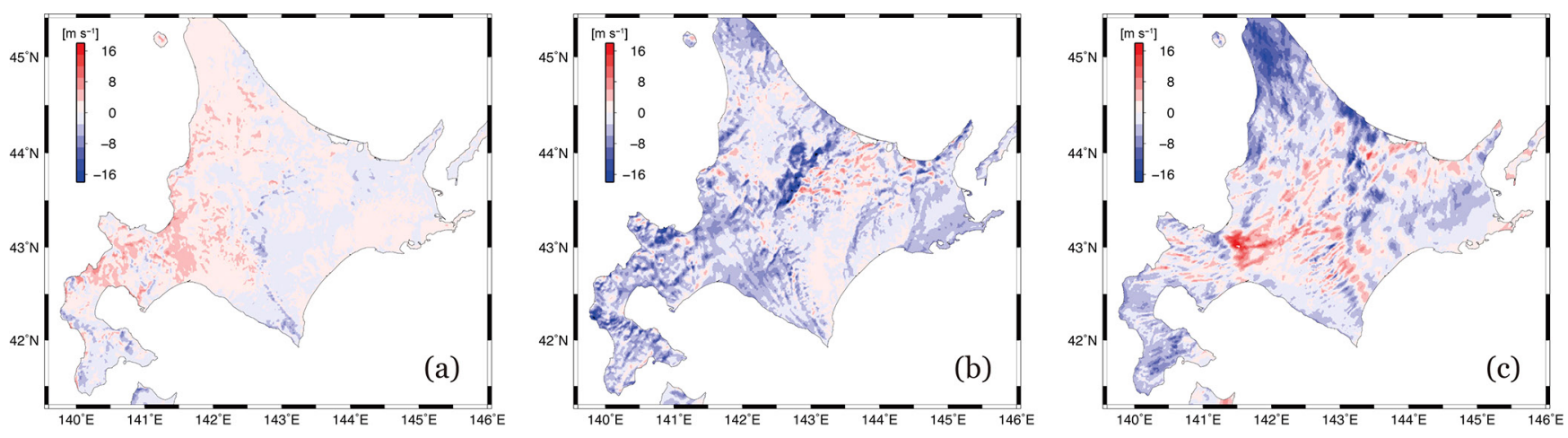

Fig. 3. Difference of the surface wind in the PGW climate (Case II) from that in the current climate at (a) 0600 UTC 7 September, (b) 1800 UTC 7 September, and (c) 0600 UTC 8 September. The difference means the wind on the warming climate minus the wind on the current climate. 
Table 2. Spatial means averaged over the land areas in the innermost domain for the temporal averaged $\left(u_{\text {mean }}\right)$ and the maximum wind speed $\left(u_{\max }\right)$ from 0300 UTC 7 September to 0000 UTC 9 September.

\begin{tabular}{|c|c|c|c|c|c|c|}
\hline \multirow{2}{*}{ Case } & \multirow{2}{*}{ Current } & \multicolumn{5}{|c|}{ Pseudo Global Warming } \\
\hline & & I & II & IIa & $\mathrm{IIb}$ & IIc \\
\hline$u_{\text {mean }}\left(\mathrm{m} \mathrm{s}_{-1}^{-1}\right)$ & 10.1 & 9.2 & 8.3 & 8.4 & 8.2 & 7.9 \\
\hline$u_{\max }\left(\mathrm{m} \mathrm{s}^{-1}\right)$ & 24.7 & 22.0 & 23.1 & 22.6 & 23.4 & 23.4 \\
\hline
\end{tabular}

the maximum wind. The average wind in Case II is weaker than that in Case I and the maximum wind in Case II is stronger. This is because the typhoon becomes weakened more rapidly in Case II than in Case I, despite that the typhoon center moves closer to Hokkaido (Fig. 2).

\section{Environmental conditions in the higher-latitude region}

We explore causes for the reduction in surface winds under the PGW condition. The reduced wind speeds over the Hokkaido area can be seen irrespective of the different setup of the PGW conditions, Case I and II, and the different future patterns of SST, Case IIa, IIb and IIc. In the following, we focus on Case II, in which the rapid weakening of the typhoon occurs over the track similar to that in the current climate and the intensity is weaker in the PGW condition than in the current climate, and examine changes of environmental conditions surrounding the typhoon center from 0000 UTC 7 September to 0000 UTC 8 September. Here, we use three environmental factors: SST, vertical shear, and meridional gradient of temperature, which are relevant to an extratropical transition by Jones et al. (2003).

Firstly, the change in SST between the current and the warming condition is examined. SST increases under the PGW condition (not shown). In terms of the increased SST, the maintenance of the typhoon intensity is expected. Jones et al. (2003) indicated that strong meridional gradients of SST also promote the transition. The change in the SST gradient due to the warming climate is indistinctive (not shown).

Secondly, the change in vertical shear is examined. We use winds at the levels of $850 \mathrm{hPa}$ and $200 \mathrm{hPa}$ for calculating the shear, and the shear is averaged over the area within the $500 \mathrm{~km}$ radius from the typhoon center. This radius is used for the analysis in the cyclone phase space (Hart 2003). Figure 4 shows temporal variations of the vertical wind shear at the position of the typhoon center for every 6-hr from 0000 UTC 7 September (open circles), called as a current time, and at the future position of the center for the subsequent every 3-hr from the each current time (closed circles). To consider a time variation of the shear while the typhoon moves, the current time are dealt with for four different times. The future shears (closed circles) are led from the wind distribution at the current time using the future positions of the typhoon. Time progression from 0000 UTC 7 September corresponds to the typhoon moving to the high latitude, and each variation expresses the shear which the typhoon undergoes at the current time and the subsequent future times. The shape of the variation is similar between both climates. Figure 2 shows that the typhoon moving in
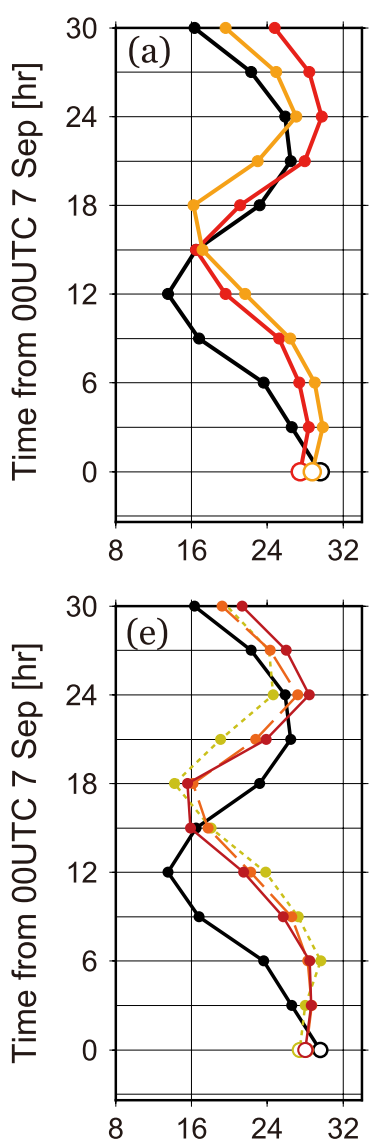
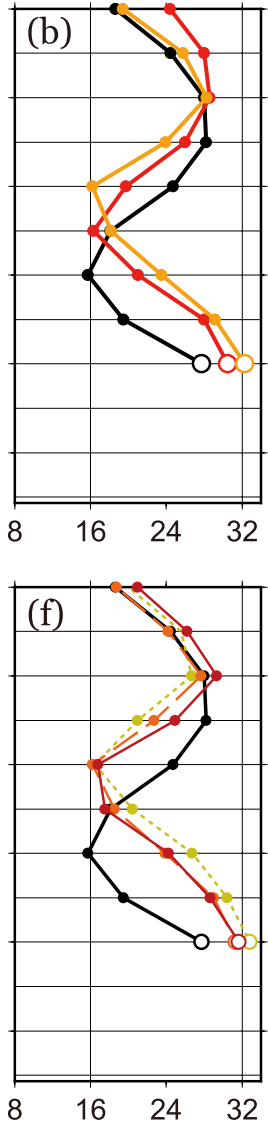
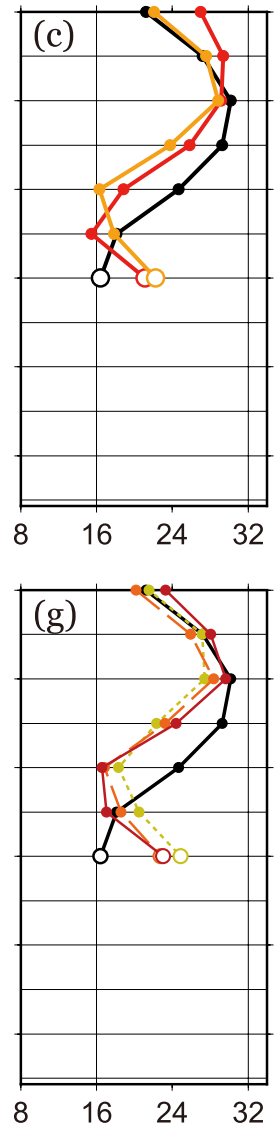

Averaged shear $\left[\mathrm{m} \mathrm{s}^{-1}\right]$
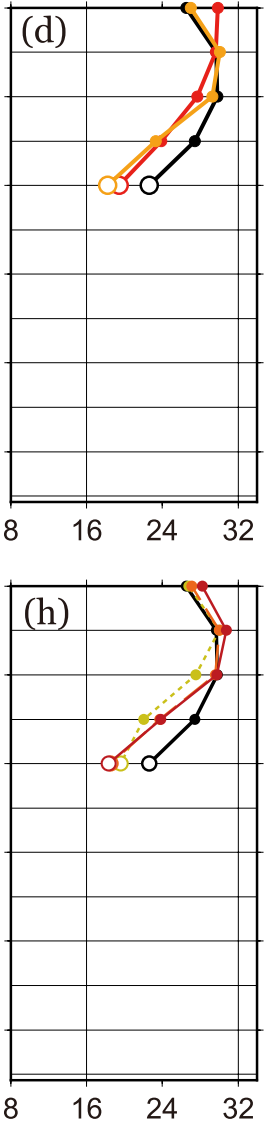

Fig. 4. Temporal variations of the vertical wind shear $\left(\mathrm{m} \mathrm{s}^{-1}\right)$ between the levels of $850 \mathrm{hPa}$ and 200 hPa around the typhoon center. Open circle is the shear at the current time, (a, e) 0000 UTC, (b, f) 0600 UTC, (c, g) 1200 UTC, and (d, h) 1800 UTC of 7 September, and closed circles are that at the subsequent every 3-hr from the each current time. Black line indicates the result in the current climate. Upper panels indicate the results in the PGW-Case I (red) and the PGW-Case II (orange). Bottom panels indicate the results in the PGW-Case IIa (solid), the PGW-Case IIb (dash), and the PGW-Case IIc (dotted). 

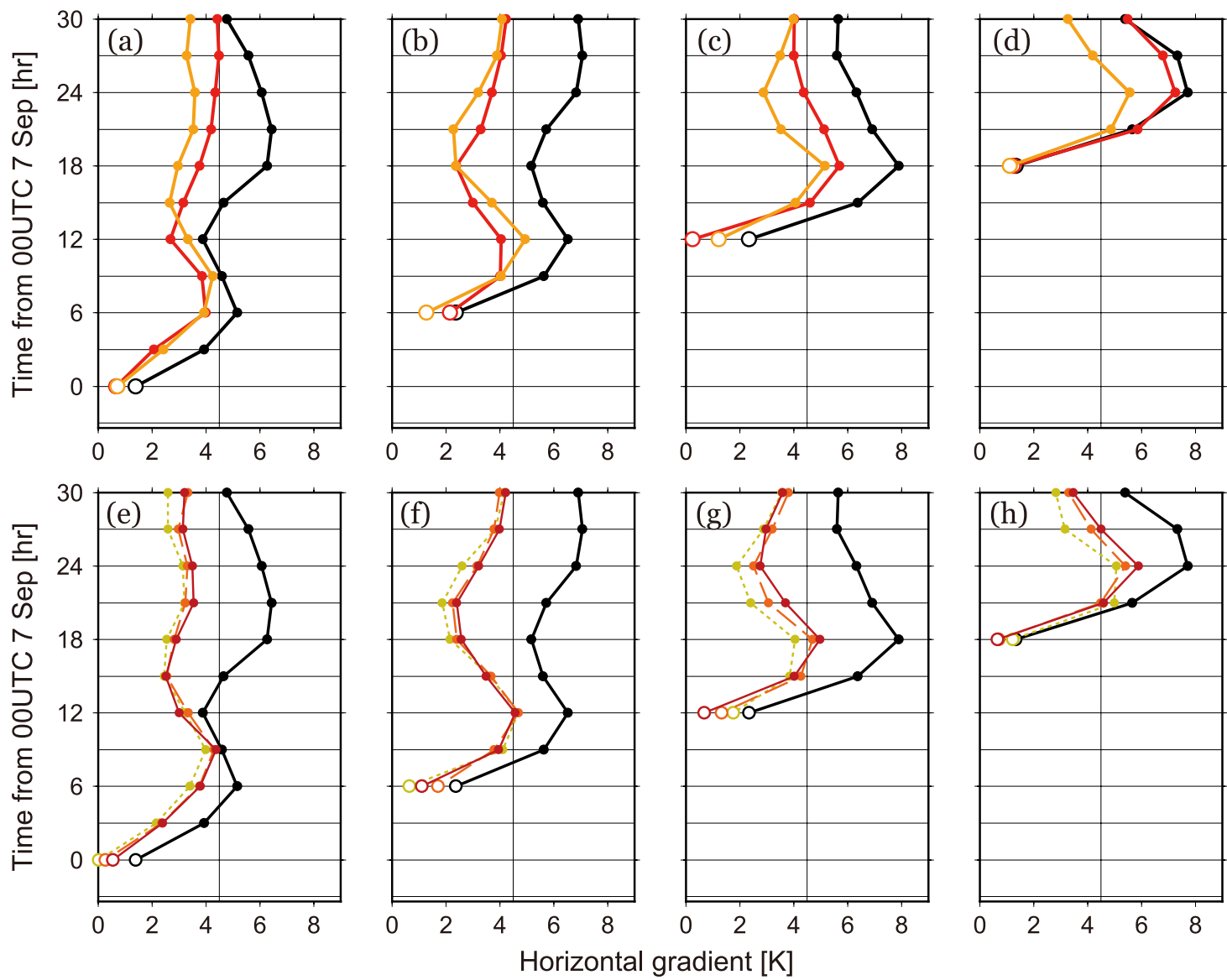

Fig. 5. The same as Fig. 4, but for the meridional gradient of temperature (K) at the level of $500 \mathrm{hPa}$.

the warming climate about 3-hr behind the moving in the current climate during the target period. When we take account of the delay, the vertical shear in the current climate at a time is comparable with the shear in the warming climate 3-hr later from the time.

Finally, the meridional gradient of the temperature is examined. The temporal variation on the meridional gradient of the temperature is shown on Fig. 5. The gradient is the subtraction of the potential temperature (PT) at the level of $500 \mathrm{hPa}$ around the typhoon center, $\mathrm{PT}_{N}-\mathrm{PT}_{S}$. $\mathrm{PT}_{N}$ is the average over the northern half part of the area within the $500 \mathrm{~km}$ radius from the center, and $\mathrm{PT}_{S}$ over the southern half part of that. The gradient is smaller in the warming climate than in the current climate even when we consider the time lag of 3-hr on the typhoon moving under the warming condition. The small gradient reflects a characteristic that temperature more increases by global warming in the high-latitude region and more over the land area (not shown). Thus, the difference of gradient between the two climate conditions becomes large at the relatively latter time when the typhoon moves to the high latitude and is close to the land area. The meridional mean temperature change by global warming in the upper and lower troposphere is comparable to that in Collins et al. (2013). The characteristic of the change at the $500 \mathrm{hPa}$ level is the same as that in the lower troposphere. The similar feature is found in the different scenarios of the underlying global warming (Knutti and Sedlacek 2013). The tendency of the weakened baroclinicity due to the smaller gradient suggests that the atmospheric environment with the PGW condition is more unfavorable for extratropical transitions than that with the current condition. Therefore, the typhoon under the PGW condition becomes weak without the completed transition. The environment around the typhoon center with the different patterns of SST setting (Case IIa, IIb, and IIc) also represents the similar variation.

\section{Summary}

To investigate an impact of global warming on a typhoon and the resultant windstorm in a higher-latitude region, we conducted numerical experiments for Typhoon Songda under two conditions: the current climate and the PGW condition. The simulated typhoon at its maturity is more intensified in the PGW condition, and subsequently weakens more rapidly over the Sea of Japan to the similar (but a little weaker) intensity as the typhoon in the current condition. Because of the change of typhoon tracks or the weak intensity under the PGW condition, spatial means for the temporal average and the maximum wind at each grid over Hokkaido become weakened in the PGW condition while the typhoon passes through Hokkaido.

We assessed the difference of SST, vertical wind shear, and meridional gradient of the temperature at the $500 \mathrm{hPa}$ level around the typhoon center between the two climate conditions. The meridional gradient under the PGW condition is small over the typhoon track. This is because the increase of temperature by global warming is large in the higher-latitude region and over the land area. In comparison with the current climate, the weaker baroclinicity due to the small gradient makes the atmospheric environment stabilized, and is more unfavorable for completing an extratropical transition. The typhoon at its maturity strengthens in the future warming climate; however, the typhoon rapidly weakens while the typhoon moves to a higher-latitude region. Therefore, windstorm by the weakened typhoon in the region is expected to be reduced in the future. Comparing with the typhoon intensity in the current climate, the intensity near Hokkaido is weak in Case II, and is almost similar in Case I. To obtain a common view on whether the typhoons moving to the higher-latitude region become weaker under the warming condition than the current condition, we 
require further analyses on various cases and also need to take into account seasonal variations.

\section{Acknowledgments}

This work was conducted under the framework of the "Precise Impact Assessments on Climate Change" of the Program for Risk Information on Climate Change (SOUSEI Program) supported by Ministry of Education, Culture, Sports, Science and Technology, Japan.

Edited by: H. Fudeyasu

\section{Supplements}

Supplementary material includes a figure.

\section{References}

Collins, M., R. Knutti, J. Arblaster, J.-L. Dufresne, T. Fichefet, P. Friedlingstein, X. Gao, W. J. Gutowski, T. Johns, G. Krinner, M. Shongwe, C. Tebaldi, A. J. Weaver, and M. Wehner, 2013: Long-term climate change: Projections, commitments and irreversibility. Climate Change 2013: The Physical Science Basis. Contribution of Working Group I to the Fifth Assessment Report of the Intergovernmental Panel on Climate Change, Stocker, T. F., D. Qin, G.-K. Plattner, M. Tignor, S. K. Allen, J. Boschung, A. Nauels, Y. Xia, V. Bex and P. M. Midgley, Eds., Cambridge University Press, Cambridge, United Kingdom and New York, NY, USA.

Christensen, J. H., K. Krishna Kumar, E. Aldrian, S.-I. An, I. F. A. Cavalcanti, M. de Castro, W. Dong, P. Goswami, A. Hall, J. K. Kanyanga, A. Kitoh, J. Kossin, N.-C. Lau, J. Renwick, D. B. Stephenson, S.-P. Xie, and T. Zhou, 2013: Climate Phenomena and their relevance for future regional climate change. Climate Change 2013: The Physical Science Basis. Contribution of Working Group I to the Fifth Assessment Report of the Intergovernmental Panel on Climate Change, Stocker, T. F., D. Qin, G.-K. Plattner, M. Tignor, S. K. Allen, J. Boschung, A. Nauels, Y. Xia, V. Bex and P. M. Midgley, Eds., Cambridge University Press, Cambridge, United Kingdom and New York, NY, USA.

Davis, C. A., and S. Low-Nam, 2001: The NCAR-AFWA tropical cyclone bogussing scheme. A Report Prepared for the Air Force Weather Agency (AFWA), 12 pp.

Fujibe, F., N. Kitabatake, K. Bessho, and S. Hoshino, 2006: Comparison of surface-wind fields between Typhoon 0418 (Songda) and Typhoon 9119 (Mireille) in western Japan. Papers Meteor. Geophys., 57, 1-9, doi:10.2467/mripapers. 57.1.

Hart, R. E., 2003: A cyclone phase space derived from thermal wind and thermal asymmetry. Mon. Wea. Rev., 131, 585616, doi:10.1175/1520-0493(2003)131<0585:ACPSDF $>2.0$. $\mathrm{CO} ; 2$.

Hayashi, M., N. Saigusa, H. Oguma, Y. Yamagata, and G. Takao 2015: Quantitative assessment of the impact of typhoon disturbance on a Japanese forest using satellite laser altimetry. Remote Sensing of Environment, 156, 216-225, doi:10.1016/ j.rse.2014.09.028.

Hong, S.-Y., and J.-O. J. Lim, 2006: The WRF single-moment 6-class microphysics scheme (WSM6). J. Korean Meteor. Soc., 42, 129-151.

Jones, S. C., P. A. Harr, J. Abraham, L. F. Bosart, P. J. Bowyer, J. L. Evans, D. E. Hanley, B. N. Hanstrum, R. E. Hart, F. Lalaurette, M. R. Sinclair, R. K. Smith, and C. Thorncroft, 2003: The extratropical transition of tropical cyclones: Forecast challenges, current understanding, and future directions. Wea. Forecasting, 18, 1052-1092.
Klein, P. M., P. A. Harr, and R. L. Elsberry, 2000: Extratropical transition of western north pacific tropical cyclones: An overview and conceptual model of the transformation stage. Wea. Forecasting, 15, 373-395.

Knutson, T. R., J. L. McBride, J. Chan, K. Emanuel, G. Holland, C. Landsea, I. Held, J. P. Kossin, A. K. Srivastava, and M. Sugi, 2010: Tropical cyclones and climate change. Nature Geoscience, 157-163, doi:10.1038/ngeo779.

Kitabatake, N., 2013: A extratropical transition of typhoon. Meteor. Res. Note, 226, 127-148 (in Japanese).

Kitabatake, N., S. Hoshino, K. Bessho, and F. Fujibe, 2007: Structure and intensity change of Typhoon Songda (0418) undergoing extratropical transition. Papers Meteor. Geophys., 58, 135-153, doi:10.2467/mripapers.58.135.

Knutti, R., and J. Sedlacek, 2013: Robustness and uncertainties in the new CMIP5 climate model projections. Nature Climate Change, 3, 369-373, doi:10.1038/nclimate1716.

Kobayashi, S., Y. Ota, Y. Harada, A. Ebita, M. Moriya, H. Onoda, K. Onogi, H. Kamahori, C. Kobayashi, H. Endo, K. Miyaoka, and K. Takahashi, 2015: The JRA-55 reanalysis: General specifications and basic characteristics. J. Meteor. Soc. Japan, 93, 5-48, doi:10.2151/jmsj.2015-001.

Lackmann, G. M., 2015: Hurricane Sandy before 1900 and after 2100. Bull. Amer. Meteor. Soc., 96, 547-560, doi:10.1175/ BAMS-D-14-00123.1.

Mizuta, R., H. Yoshimura, H. Murakami, M. Matsueda, H. Endo, T. Ose, K. Kamiguchi, M. Hosaka, M. Sugi, S. Yukimoto, S. Kusunoki, and A. Kitoh, 2012: Climate simulations using MRI-AGCM3.2 with 20-km grid. J. Meteor. Soc. Japan, 90A, 233-258, doi:10.2151/jmsj.2012-A12.

Mizuta, R., O. Arakawa, T. Ose, S. Kusunoki, H. Endo, and A. Kitoh, 2014: Classification of CMIP5 future climate responses by the tropical sea surface temperature changes. SOLA, 10, 167-171, doi:10.2151/sola.2014-035.

Murakami, H., Y. Wang, H. Yoshimura, R. Mizuta, M. Sugi, E. Shindo, Y. Adachi, S. Yukimoto, M. Hosaka, S. Kusunoki, T. Ose, and A. Kitoh, 2012: Future changes in tropical cyclone activity projected by the new high-resolution MRI-AGCM. $J$. Climate, 25, 3237-3260, doi:10.1175/JCLI-D-11-00415.1.

Oku, Y., T. Takemi, H. Ishikawa, S. Kanada, and M. Nakano, 2010: Representation of extreme weather during a typhoon landfall in regional meteorological simulations: A model intercomparison study for Typhoon Songda (2004). Hydrol. Res. Lett., 4, 1-5, doi:10.3178/hrl.4.1.

Sano, T., T. Hirano, N. Liang, R. Hirata, and Y. Fujinuma, 2010: Carbon dioxide exchange of a larch forest after a typhoon disturbance. Forest Ecology and Management, 260, 22142223, doi:10.1016/j.foreco.2010.09.026.

Sato, T., F. Kimura, and A. Kitoh, 2007: Projection of global warming onto regional precipitation over Mongolia using a regional climate model. J. Hydrol., 333, 144-154, doi: 10.1016/j.jhydrol.2006.07.023.

Skamarock, W. C., J. B. Klemp, J. Dudhia, D. O. Gill, D. M. Barker, M. G. Duda, X.-Y. Huang, W. Wang, and J. G. Powers, 2008: A description of the advanced research WRF version 3. NCAR Tech. Note, NCAR/TN-475+STR, doi: 10.5065/D68S4MVH.

Takemi, T., S. Nomura, Y. Oku, and H. Ishikawa, 2012: A regional-scale evaluation of changes in environmental stability for summertime afternoon precipitation under global warming from super-high-resolution GCM simulations: A study for the case in the Kanto Plain. J. Meteor. Soc. Japan, 90A, 189212, doi:10.2151/jmsj.2012-A10.

Manuscript received 21 January 2016, accepted 1 April 2016 SOLA: https://www.jstage.jst.go.jp/browse/sola/ 